Pacific Journal of Mathematics

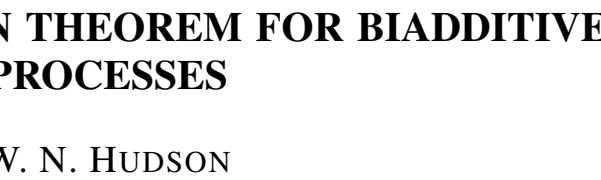




\title{
A DECOMPOSITION THEOREM FOR BIADDITIVE PROCESSES
}

\author{
W. N. HuDson
}

This paper treats a class of stochastic processes called biadditive processes and gives a proof of a decomposition of their sample functions. Informally, a biadditive proces $X(s, t)$ is a process indexed by two time parameters whose "increments" over disjoint rectangles are independent. The increments of such a process are the second differences

$$
X\left(s_{2}, t_{2}\right)-X\left(s_{1}, t_{2}\right)-X\left(s_{2}, t_{1}\right)+X\left(s_{1}, t_{1}\right)
$$

where $s_{1}<s_{2}$ and $t_{1}<t_{2}$. The decomposition theorem states that every centered biadditive process is the sum of four independent biadditive processes: one with jumps in both variables, two with jumps in one variable and continuous in probability in the other, and a fourth process which is jointly continuous in probability.

This decomposition is similar to one for processes with independent increments and in the proofs of both results a major role is played by the theory of centralized sums of independent random variables.

More formally, let $P_{1}=\left\{s_{1}, s_{2}, \cdots, s_{n}\right\}$ and $P_{2}=\left\{t_{1}, t_{2}, \cdots, t_{m}\right\}$ be two partitions of $\left[0, s_{n}\right]$ and $\left[0, t_{m}\right]$ respectively. Define $P_{1} \times P_{2}$ to be the corresponding partition of $\left[0, s_{n}\right] \times\left[0, t_{m}\right]$ into rectangles whose vertices are the $\left(s_{i}, t_{j}\right)$ 's. Let $\Delta_{i j}$ denote the increment

$$
\Delta_{i j}=X\left(s_{i+1}, t_{j+1}\right)-X\left(s_{i}, t_{j+1}\right)-X\left(s_{i+1}, t_{j}\right)+X\left(s_{i}, t_{j}\right)
$$

over the rectangle with vertices $\left(s_{i+1}, t_{j+1}\right),\left(s_{i}, t_{j+1}\right),\left(s_{i+1}, t_{j}\right)$ and $\left(s_{i}, t_{j}\right)$. Then if the increments

$$
\left\{\Delta_{i j}: i=0,1, \cdots, n-1, j=0,1, \cdots, m-1\right\}
$$

corresponding to any partition $P_{1} \times P_{2}$ are independent and if $X(s, 0)=$ $0=X(0, t)$ for all $s$ and $t$ not less than zero, $X(s, t)$ is called biadditive.

It is easy to construct some examples of biadditive processes. For instance, if $\left\{Y_{i j}\right\}_{i, j=0}^{\infty}$ is a doubly infinite sequence of independent random variables, then it is easy to see that the process

$$
X(s, t)=\sum_{i<s} \sum_{j<t} Y_{i j}
$$

is biadditive. A nontrivial example of a biadditive process is obtained when the space $C_{2}$ of continuous functions of two variables on $[0, \infty) \times$ $[0, \infty)$ is given the Wiener-Yeh measure and the process $X(s, t)$ is the 
coordinate process (see [3]). In [1] it was shown that the only biadditive processes with versions having continuous sample surfaces are Gaussian with continuous mean and variance functions, a result analogous to the one parameter case.

In order to facilitate the reading of this note, a short summary without proofs of some results of the theory of centralized sums is given in $\S 2$. A very nice account with proofs is given in the lecture notes by K. Itô (see [2]).

\section{Summary of the theory of centralized sums.}

Definition (J. L. Doob). If $X$ is a random variable with probability distribution $\mu$, the central value $\gamma(X)$ of $X$ is defined to be the unique real number $\gamma$ such that

$$
\int_{-\infty}^{\infty} \arctan (x-\gamma) \mu(d x)=0
$$

The dispersion $\delta(X)$ of $X$ is defined to be

$$
\delta(X)=-\log \int_{-\infty}^{\infty} \int_{-\infty}^{\infty} \exp \{-|x-y|\} \mu(d x) \mu(d y) .
$$

\section{Basic Properties.}

(2.1) If $\beta$ is any number, $\gamma( \pm X+\beta)= \pm \gamma(X)+\beta$ and $\delta( \pm X+\beta)=\delta(X)$. (2.2) If $c$ is any number and $X=c$ a.s., then $\gamma(X)=c$ and $\delta(X)=0$. (2.3) A sequence of random variables $\left\{X_{n}\right\}$ converges in probability to a random variable $X$ if and only if $\gamma\left(X_{n}\right) \rightarrow \gamma(X)$ and $\delta\left(X_{n}-X\right) \rightarrow 0$. (2.4) If $X$ and $Y$ are independent random variables, then $\delta(X+Y) \geqq$ $\delta(X)$. Furthermore, $\delta(X+Y)=\delta(X)$ if and only if $Y$ is constant a.s.

Centralized Sums. Let $\left\{X_{n}\right\}$ be a sequence of independent random variables and let $S_{n}=\sum_{1}^{n} X_{k}$. Then the sequence of dispersions $\left\{\delta\left(S_{n}\right)\right\}$ is a nondecreasing set of real numbers. There are two cases

(a) If $\lim _{n} \delta\left(S_{n}\right)<\infty$, then $\left\{S_{n}-\gamma\left(S_{n}\right)\right\}$ converges a.s.

(b) If $\lim _{n} \delta\left(S_{n}\right)=\infty$, then for every choice of a sequence of constants $\left\{c_{n}\right\},\left\{S_{n}-c_{n}\right\}$ diverges a.s.

Let $\left\{X_{\alpha}\right\}_{\alpha \in A}$ be a countable family of independent random variables. Let $F$ be a finite subset of $A$ and set $S_{F}=\sum_{\alpha \in F} X_{\alpha}$ and $S_{F}^{*}=S_{F}-\gamma\left(S_{F}\right)$. $S_{F}$ is called the partial sum over $F$ and $S_{F}^{\cdot}$ is called the centralized partial sum over $F$. We write $S_{F}^{\cdot}=\sum_{\alpha \in F}^{\cdot} X_{\alpha}$. (Also we will use $X+Y$ for $X+Y-\gamma(X+Y)$ and $X-Y$ for $X-Y-\gamma(X-Y)$. Let

$$
\delta(A)=\sup _{F} \delta\left(S_{F}\right)
$$


where $F$ ranges over all finite subsets of $A$.

Theorem 2.1. Suppose that $\delta(A)<\infty$ and that $\left\{F_{n}\right\}$ is a nondecreasing sequence of finite sets such that $F_{1} \subset F_{2} \subset \cdots \rightarrow A$. Then

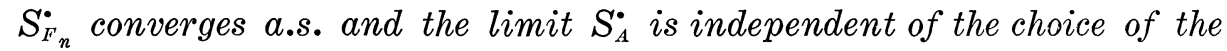
sequence $\left\{F_{n}\right\}$ of finite subsets. Furthermore

$$
\gamma\left(S_{A}^{\cdot}\right)=0 \text { and } \delta\left(S_{A}^{*}\right)=\delta(A) .
$$

Centralized sums behave in a very nice way. More precisely,

THEOREM 2.2. Let $\left\{X_{\alpha}\right\}_{\alpha \in A}$ be a countable family of independent random variables such that $\delta(A)<\infty$.

(a) If $A=\cup A_{n}$ (disjoint), then $S_{A}^{\cdot}=\sum \cdot S_{A_{n}}^{\cdot}$ a.s.

(b) If $A_{n} \uparrow A$, then $S_{A_{n}}^{\cdot} \rightarrow S_{A}^{\cdot}$ a.s. $S_{B}^{\cdot}$ a.s.

(c) If $B \subset A$ and $B_{k} \downarrow B$, where $B_{k} \subset A$ for all $k$, then $S_{B_{k}} \rightarrow$

\section{The decomposition theorem.}

Definition. A centralized biadditive process $X(s, t)$ is for each $s$ the sum of independent jumps occurring before time $t$ if there exists a countable family of independent random processes $\left\{Z_{t}(s)\right\}$ such that

$$
X(s, t)=\sum_{y \leqq t} \cdot Z_{y}(s)
$$

$X(s, t)$ is said to be the sum of independent jumps occurring before time $(s, t)$ if there exists a countable family of independent random variables $\{T(x, y)\}$ such that

$$
X(s, t)=\sum_{X \leq s} \cdot \sum_{y \leq t} \cdot T(x, y)
$$

Theorem 3.1. Let $\{X(s, t): s, t \geqq 0\}$ be a biadditive process. Then $X(s, t)$ can be written as the sum of a deterministic part $f(s, t)$ and four independent centralized biadditive processes $X_{1}(s, t), X_{2}(s, t), X_{3}(s, t)$, and $X_{4}(s, t)$ which have the following properties:

(a) $X_{1}(s, t)$ is the sum of independent jumps occurring before time $(s, t)$.

(b) $X_{2}(s, t)$ is for each $t \geqq 0$ continuous in probability in $s$ and for each $s$ is the sum of independent jumps occurring before time $t$.

(c) $X_{3}(s, t)$ is for each $s \geqq 0$ continuous in probability in $t$ and for each $t$ is the sum of independent jumps occurring before time s.

(d) $X_{4}(s, t)$ is continuous in probability on $[0, \infty) \times[0, \infty)$.

4. Proof of the decomposition theorem. The first lemma follows immediately from the definition of biadditive processes. 
Lemma 4.1. Let $\left\{X_{\alpha}(s): 0 \leqq s\right\}_{\alpha}$ be a finite set of independent additive processes such that $X_{\alpha}(0)=0$ for all $\alpha$. Then

$$
Y(s, t)=\sum_{0<\alpha<t} X_{\alpha}(s)
$$

is biadditive.

Definition. We write $s_{n} \downarrow s$ if $s_{1}>s_{2}>\cdots>s_{n}>\cdots$ and $\lim _{n} s_{n}=s$. Similarly $s_{n} \uparrow s$ means $s_{1}<s_{2}<\cdots<s$ and $\lim _{n} s_{n}=s$.

Theorem 4.1. Let $X(s, t)$ be a centralized biadditive process. Then if $s_{n} \uparrow s$ and $t_{n} \downarrow t, P-\lim _{n \rightarrow \infty} X\left(s_{n}, t_{n}\right)$ exists. Furthermore if $\left\{\left(s_{n}^{\prime}, t_{n}^{\prime}\right)\right\}$ is another sequence of points such that $s_{n}^{\prime} \uparrow s$ and $t_{n}^{\prime} \downarrow t$, then $P-$ $\lim _{n \rightarrow \infty} X\left(s_{n}^{\prime}, t_{n}^{\prime}\right)$ exists and is equal to $P-\lim _{n \rightarrow \infty} X\left(s_{n}, t_{n}\right)$.

Proof. We show that in fact the almost everywhere limits, exist, the exceptional set depending on the particular sequence. Let $s_{n} \uparrow s$ and $t_{n} \downarrow t$. Then

$$
\begin{aligned}
X\left(s_{n}, t_{n}\right)= & X\left(s_{1}, t_{1}\right)+\sum_{r=1}^{n-1}\left[X\left(s_{r}, t_{r+1}\right)-X\left(s_{r}, t_{r}\right)\right] \\
& +\sum_{r=1}^{n-1}\left[X\left(s_{r+1}, t_{r+1}\right)-X\left(s_{r}, t_{r+1}\right)\right] .
\end{aligned}
$$

Since each of the sums on the right are sums of independent random variables and the dispersions of their partial sums are dominated by $\delta\left[X\left(s, t_{1}\right)\right]<\infty$, each sum when centralized converges a.s. It follows that $X\left(s_{n}, t_{n}\right)+k_{n}$ converges a.s. for some sequence of constants $\left\{k_{n}\right\}$. Then

$$
\gamma\left(\lim _{n \rightarrow \infty}\left[X\left(s_{n}, t_{n}\right)+k_{n}\right]\right)=\lim _{n \rightarrow \infty}\left\{\gamma\left(X\left(s_{n}, t_{n}\right)\right)+k_{n}\right\}=\lim _{n \rightarrow \infty} k_{n}
$$

exists and hence $X\left(s_{n}, t_{n}\right)=\left(X\left(s_{n}, t_{n}\right)+k_{n}\right)-k_{n}$ converges a.s.

To show that $\lim _{n \rightarrow \infty} X\left(s_{n}^{\prime}, t_{n}^{\prime}\right)=\lim _{n \rightarrow \infty} X\left(s_{n}, t_{n}\right)$, form a new sequence $\left(\bar{s}_{n}, \bar{t}_{n}\right)$ converging monotonically to $(s, t)$ by alternating points from $\left\{\left(s_{n}, t_{n}\right)\right\}$ and $\left\{\left(s_{n}^{\prime}, t_{n}^{\prime}\right)\right\}$.

From now on let $X(s, t)$ denote a centralized biadditive process. The last theorem and its obvious counterparts justify the notation

$$
\begin{aligned}
& X(s+, t+)=P-\lim _{n \rightarrow \infty} X\left(s_{n}, t_{n}\right) \quad \text { if } \quad s_{n} \downarrow s \text { and } t_{n} \downarrow t \\
& X(s-, t+)=P-\lim _{n \rightarrow \infty} X\left(s_{n}, t_{n}\right) \quad \text { if } \quad s_{n} \uparrow s \text { and } t_{n} \downarrow t \\
& X(s+, t-)=P-\lim _{n \rightarrow \infty} X\left(s_{n}, t_{n}\right) \quad \text { if } \quad s_{n} \downarrow s \text { and } \quad t_{n} \uparrow t
\end{aligned}
$$




$$
\begin{aligned}
X(s-, t-) & =P-\lim _{n \rightarrow \infty} X\left(s_{n}, t_{n}\right) \quad \text { if } s_{n} \uparrow s \text { and } t_{n} \uparrow t \\
X(0-, t) & =X(s, 0-)=0 \text { (convention). }
\end{aligned}
$$

Lemma 4.2. Let $0 \leqq s, t$. If $\delta\left\{X\left(s_{0}+, t_{0}\right)-X\left(s_{0}-, t_{0}\right)\right\}>0$ for some $t_{0}$, then $\delta\left\{X\left(s_{0}+, t\right)-X\left(s_{0}-, t\right)\right\}>0$ for all $t \geqq t_{0}$. Similarly if $\delta\left\{X\left(s_{0}, t_{0}+\right)-X\left(s_{0}, t_{0}-\right)\right\}>0$ for some $s_{0}$, then $\delta\left\{X\left(s, t_{0}+\right)-X\left(s, t_{0}-\right)\right\}>0$ for all $s \geqq s_{0}$.

Proof. Suppose that for some $t_{0}, \delta\left\{X\left(s_{0}+, t_{0}\right)-X\left(s_{0}-, t_{0}\right)\right\}>0$. If $t \geqq t_{0}$,

$$
X\left(s_{0}+, t\right)-X\left(s_{0}-, t\right)=X\left(s_{0}+, t_{0}\right)-X\left(s_{0}-, t_{0}\right)+\Delta
$$

where

$$
\Delta=X\left(s_{0}+, t\right)-X\left(s_{0}+, t_{0}\right)-X\left(s_{0}-, t\right)+X\left(s_{0}-, t_{0}\right)
$$

is independent of $X\left(s_{0}+, t_{0}\right)-X\left(s_{0}-, t_{0}\right)$. Hence

$$
0<\delta\left\{X\left(s_{0}+, t_{0}\right)-X\left(s_{0}-, t_{0}\right)\right\} \leqq \delta\left\{X\left(s_{0}+, t\right)-X\left(s_{0}-, t\right)\right\} .
$$

Definition. The line $s=s_{0}$ is a line of discontinuity for the biadditive process $X(s, t)$ if for some $t \geqq 0, \delta\left\{X\left(s_{0}+, t\right)-X\left(s_{0}-, t\right)\right\}>0$. Similarly $t=t_{0}$ is a line of discontinuity if for some $s \geqq 0, \delta\left\{X\left(s, t_{0}+\right)-\right.$ $\left.X\left(s, t_{0}\right)\right\}>0$. Let

$$
D_{1}=\{s \geqq 0: \exists t \geqq 0 \text { such that } \delta[X(s+, t)-X(s-, t)]>0\}
$$

and

$$
D_{2}=\{t \geqq 0: \exists s \geqq 0 \text { such that } \delta[X(s, t+)-X(s, t-)]>0\} .
$$

It is easy to see that $D_{1}$ and $D_{2}$ are countable sets. $D_{1}$ is the union over all positive integers $n$ of the countable sets of fixed points of discontinuity of the additive process $Y_{n}(s)=X(s, n)$. (This follows from Lemma 4.2.)

From now on $X(s, t)$ will denote a centralized biadditive process. We define

$$
\begin{aligned}
X_{1}(s, t) & \\
= & \sum_{0 \leq x<s} \cdot \sum_{0 \leq y<t} \cdot\{X(x+, y+)-X(x-, y+)-X(x+, y-)+X(x-, y-)\} \\
& +\sum_{0 \leq y<t}\{X(s, y+)-X(s-, y+)-X(s, y-)+X(s-, y-)\} \\
& +\sum_{0 \leq x<s}\{X(x+, t)-X(x-, t)-X(x+, t-)+X(x-, t-)\} \\
& +\{X(s, t)-X(s-, t)-X(s, t-)+X(s-, t-)\} .
\end{aligned}
$$

All sums above and from here on are really countable since for only 
$x$ 's in $D_{1}$ and $y$ 's in $D_{2}$ are the random variables in the sums nonzero. Let

$$
Y_{1}(s, t)=X(s, t)-X_{1}(s, t)
$$

Proposition 4.1. $Y_{1}(s, t)$ and $X_{1}(s, t)$ as defined above are independent biadditive processes. Furthermore for all $s$ and $t \geqq 0$,

$$
Y_{1}(s+, t+)-Y_{1}(s-, t+)-Y_{1}(s+, t-)+Y_{1}(s-, t-)=0 .
$$

Proof. By approximating $X_{1}(s, t)$ with finite sums $X_{1}^{(n)}(s, t)$ and writing $Y_{1}^{(n)}=X-X_{1}^{(n)}$ so that $X_{1}^{(n)}$ and $Y_{1}^{(n)}$ are independent biadditive processes, we see that $X_{1}$ and $Y_{1}$ are the limits of independent biadditive processes. It follows that $X_{1}$ and $Y_{1}$ are independent biadditive processes.

To prove that

$$
Y_{1}(s+, t+)-Y_{1}(s-, t+) \dot{-} Y_{1}(s+, t-)+Y_{1}(s-, t-)=0
$$

we note that if $s_{n} \downarrow s$ and $t_{n} \downarrow t$,

$$
\begin{aligned}
& P-\lim _{n \rightarrow \infty} \sum_{0 \leq y<t_{n}}\left\{X\left(s_{n}, y+\right)-X\left(s_{n}-, y+\right)-X\left(s_{n}, y-\right)+X\left(s_{n}-, y-\right)\right\}=0 \\
& P-\lim _{n \rightarrow \infty} \sum_{0 \leq x<s_{n}}\left\{X\left(x+, t_{n}\right)-X\left(x-, t_{n}\right)-X\left(x+, t_{n}-\right)+X\left(x-, t_{n}-\right)\right\}=0 \\
& P-\lim _{n \rightarrow \infty}\left\{X\left(s_{n}, t_{n}\right)-X\left(s_{n}-, t_{n}\right)-X\left(s_{n}, t_{n}-\right)+X\left(s_{n}-, t_{n}-\right)\right\}=0 .
\end{aligned}
$$

The first equality is a consequence of (2.4). Since $X$ is biadditive,

$$
\begin{aligned}
& {\left[X\left(s_{n}, t_{1}\right)-X\left(s+, t_{1}\right)\right]} \\
& \quad-\sum_{0 \leq y<t_{n}}\left\{X\left(s_{n}, y+\right)-X\left(s_{n}-, y+\right)-X\left(s_{n}, y-\right)+X\left(s_{n}-, y-\right)\right\}
\end{aligned}
$$

and

$$
\sum_{0 \leq y<t_{n}}\left\{X\left(s_{n}, y+\right)-X\left(s_{n}-, y+\right)-X\left(s_{n}, y-\right)+X\left(s_{n}-, y-\right)\right\}
$$

are independent. Hence,

$$
\begin{gathered}
\delta\left\{\sum_{0 \leqq y<t_{n}}\left\{X\left(s_{n}, y+\right)-X\left(s_{n}-, y+\right)-X\left(s_{n}, y-\right)+X\left(s_{n}-, y-\right)\right\}\right. \\
\left.\quad \leqq \hat{o}\left\{X\left(s_{n}, t_{1}\right)-X\left(s+, t_{1}\right)\right\}\right\} \rightarrow 0 \text { as } n \rightarrow \infty .
\end{gathered}
$$

Since the sum is centralized, the first equality follows by (2.3). The other two equalities follow from similar arguments. We have from Theorem 2.2

$$
\begin{aligned}
& X_{1}(s+, t+) \\
& \quad=\sum_{0 \leqq y \leqq t} \cdot \sum_{0 \leqq x} \cdot\{X(x+, y+)-X(x-, y+)-X(x+, y-)+X(x-, y-)\} .
\end{aligned}
$$


Using the basic properties of centralized sums and dispersions in a similar manner, we obtain

$$
\begin{aligned}
& X_{1}(s-, t+) \\
& \quad=\sum_{0 \leqq x<s} \cdot \sum_{0 \leqq y \leq t} \cdot\{(x+, y+)-X(x-, y+)-X(x+, y-)+X(x-, y-)\} \\
& X_{1}(s+, t-) \\
& \quad=\sum_{0 \leqq x \leqq s} \cdot \sum_{0 \leqq y<t}\{X(x+, y+)-X(x-, y+)-X(x+, y-)+X(x-, y-)\} \\
& X_{1}(s-, t-) \\
& \quad=\sum_{0 \leqq x<s} \cdot \sum_{0 \leq y<t} \cdot\{X(x+, y+)-X(x-, y+)-X(x+, y-)+X(x-, y-)\} .
\end{aligned}
$$

We obtain from these equations,

$$
\begin{aligned}
& X_{1}(s+, t+)-X_{1}(s-, t+)-X_{1}(s+, t-)-X_{1}(s-, t-) \\
& \quad=X(s+, t+)-X(s-, t+)-X(s+, t-)-X(s-, t-) .
\end{aligned}
$$

Since $Y_{1}=X-X_{1}$, the proposition is proved.

Now define

$$
X_{2}(s, t)=\sum_{0 \leqq x<s}\left\{Y_{1}(x+, t)-Y_{1}(x-, t)\right\}+\left\{Y_{1}(s, t)-Y_{1}(s-, t)\right\}
$$

and

$$
Y_{2}(s, t)=Y_{1}(s, t) \doteq X_{2}(s, t) .
$$

Proposition 4.2. $X_{2}(s, t)$ and $Y_{2}(s, t)$ are independent biadditive processes. Furthermore, for all $s$ and $t$

$$
X_{2}(s, t+)=X_{2}(s, t-)
$$

and

$$
Y_{2}(s+, t+)-Y_{2}(s+, t-)-Y_{2}(s-, t+)+Y_{2}(s-, t-)=0 .
$$

Proof. The fact that $X_{2}$ and $Y_{2}$ are independent biadditive processes is proved in the same way as the corresponding assertion in Proposition 4.1. Using the techniques of the theory of centralized sums, one may easily see that

$$
X_{2}(s, t+)=\sum_{0 \leq x<s}\left\{Y_{1}(x+, t+)-Y_{1}(x-, t+)\right\}+\left\{Y_{1}(s, t+)-Y_{1}(s-, t+)\right\}
$$

and

$X_{2}(s, t-)=\sum_{0 \leq x<s}\left\{Y_{1}(x+, t-)-Y_{1}(x-, t-)\right\}+\left\{Y_{1}(s, t-)-Y_{1}(s-, t-)\right\}$. 


$$
\begin{aligned}
& X_{2}(s, t+)-X_{2}(s, t-) \\
& =\sum_{0 \leqq x<s}\left\{Y_{1}(x+, t+)-Y_{1}(x-, t+)-Y_{1}(x+, t-)+Y_{1}(x-, t-)\right\} \\
& \quad+\left\{Y_{1}(s, t+)+Y_{1}(s-, t+)-Y_{1}(s, t-)+Y_{1}(s-, t-)\right\}=0
\end{aligned}
$$

by Proposition 4.1.

Since $X_{2}$ is centralized, $X_{2}(s, t+)=X_{2}(s, t-)$ follows. An almost identical argument shows that $X_{2}(s+, t+)=X_{2}(s+, t-)$ and

$$
X_{2}(s-, t+)=X_{2}(s-, t-) \text {. }
$$

The last equality follows immediately from these equations, Proposition 4.1, and the definition of $Y_{2}$.

We finally define

$$
X_{3}(s, t)=\sum_{0 \leqq y<t}\left\{Y_{2}(s, y+)-Y_{2}(s, y-)+\left\{Y_{2}(s, t)-Y_{2}(s, t-)\right\}\right.
$$

and

$$
X_{4}(s, t)=Y_{2}(s, t) \doteq X_{3}(s, t) .
$$

Proposition 4.3. $\quad X_{3}$ and $X_{4}$ are independent biadditive processes. Also for all $s$ and $t$

$$
X_{3}(s+, t)=X_{3}(s-, t) .
$$

Furthermore, $X_{4}$ is continuous in probability since for all $s$ and $t$

$$
X_{4}(s+, t+)=X_{4}(s-, t-) \text {. }
$$

Proof. The fact that $X_{3}$ and $X_{4}$ are independent follows just as similar previous assertions. Since

$$
X_{3}(s+, t)=\sum_{0 \leqq y<t}\left\{Y_{2}(s+, y+)-Y_{2}(s+, y-)\right\} \dot{+}\left\{Y_{2}(s+, t)-Y_{2}(s+, t-)\right\}
$$

and

$$
X_{3}(s-, t)=\sum_{0 \leqq y<t}\left\{Y_{2}(s-, y+)-Y_{2}(s-, y-)\right\} \dot{+}\left\{Y_{2}(s-, t)-Y_{2}(s-, t-)\right\},
$$

we have

$$
\begin{aligned}
& X_{3}(s+, t)-X_{3}(s-, t) \\
& =\sum_{0 \leq y<t}\left\{Y_{2}(s+, y+)-Y_{2}(s+, y-)-Y_{2}(s-, y+)+Y_{2}(s-, y-)\right\} \\
& \quad+\left\{Y_{2}(s+, t)-Y_{2}(s+, t-)-Y_{2}(s-, t)+Y_{2}(s-, t-)\right\}=0
\end{aligned}
$$

by Proposition 4.2 .

Since $X_{3}$ is centralized, $X_{3}(s+, t)=X_{3}(s-, t)$. 
Similar computations yield

$$
X_{3}(s+, t+)=\sum_{0 \leqq y \leqq t}\left\{Y_{2}(s+, y+)-Y_{2}(s+, y-)\right\}
$$

and

$$
X_{3}(s-, t-)=\sum_{0 \leqq y<t}\left\{Y_{2}(s-, y+)-X_{2}(s-, y-)\right\}
$$

Thus

$$
\begin{aligned}
& X_{3}(s+, t+)-X_{3}(s-, t-) \\
& =\sum_{0 \leqq y<t}\left\{Y_{2}(s+, y+)-Y_{2}(s-, y+)-Y_{2}(s+, y-)+Y_{2}(s-, y-)\right\} \\
& \quad+\left\{Y_{2}(s+, t+)-Y_{2}(s+, t-)\right\} \\
& =Y_{2}(s+, t+)-Y_{2}(s+, t-)
\end{aligned}
$$

by Proposition 4.2. From the definition of $X_{4}$ it follows that

$$
X_{4}(s+, t+)-X_{4}(s-, t-)=0 .
$$

Since $X_{4}$ is centralized, the proposition is proved.

The decomposition theorem now follows immediately from Propositions 4.1, 4.2, and 4.3 and from the definitions of $X_{1}, X_{2}, X_{3}$ and $X_{4}$.

\section{REFERENCES}

1. W. N. Hudson, Continuity of sample functions of biadditive processes, Pacific J. Math., 42 (1972), 345-360.

2. K. Itô, Stochastic Processes (Lecture Notes), Matematisk Institut, Aarhus Universitat 1969.

3. J. Yeh, Wiener measure in the space of function of two variables, Trans. Amer. Math. Soc., 95 (1960), 433-450.

Received March 10, 1972. The author wishes to thank Professor Howard Tucker for suggesting this problem.

UNIVERSITY OF CALIFORNIA

SANTA Barbara, California 



\section{PACIFIC JOURNAL OF MATHEMATICS}

\section{EDITORS}

\author{
H. SAMELSON \\ Stanford University \\ Stanford, California 94305 \\ C. R. HOBBY \\ University of Washington \\ Seattle, Washington 98105
}

\section{J. DuGundJI}

Department of Mathematics University of Southern California Los Angeles, California 90007

RICHARD ARENS

University of California

Los Angeles, California 90024

\section{ASSOCIATE EDITORS}
E. F. BECKENBACH
B. H. NeumanN
F. WOLF
K. YOSHIDA

\section{SUPPORTING INSTITUTIONS}

\author{
UNIVERSITY OF BRITISH COLUMBIA \\ CALIFORNIA INSTITUTE OF TECHNOLOGY \\ UNIVERSITY OF CALIFORNIA \\ MONTANA STATE UNIVERSITY \\ UNIVERSITY OF NEVADA \\ NEW MEXICO STATE UNIVERSITY \\ OREGON STATE UNIVERSITY \\ UNIVERSITY OF OREGON \\ OSAKA UNIVERSITY
}

\author{
UNIVERSITY OF SOUTHERN CALIFORNIA \\ STANFORD UNIVERSITY \\ UNIVERSITY OF TOKYO \\ UNIVERSITY OF UTAH \\ WASHINGTON STATE UNIVERSITY \\ UNIVERSITY OF WASHINGTON \\ AMERICAN MATHEMATICAL SOCIETY \\ NAVAL WEAPONS CENTER
}

The Supporting Institutions listed above contribute to the cost of publication of this Journal, but they are not owners or publishers and have no responsibility for its content or policies.

Mathematical papers intended for publication in the Pacific Journal of Mathematics should be in typed form or offset-reproduced, (not dittoed), double spaced with large margins. Underline Greek letters in red, German in green, and script in blue. The first paragraph or two must be capable of being used separately as a synopsis of the entire paper. The editorial "we" must not be used in the synopsis, and items of the bibliography should not be cited there unless absolutely necessary, in which case they must be identified by author and Journal, rather than by item number. Manuscripts, in duplicate if possible, may be sent to any one of the four editors. Please classify according to the scheme of Math. Rev. Index to Vol. 39. All other communications to the editors should be addressed to the managing editor, Richard Arens, University of California, Los Angeles, California, 90024.

50 reprints are provided free for each article; additional copies may be obtained at cost in multiples of 50 .

The Pacific Journal of Mathematics is published monthly. Effective with Volume 16 the price per volume (3 numbers) is $\$ 8.00$; single issues, $\$ 3.00$. Special price for current issues to individual faculty members of supporting institutions and to individual members of the American Mathematical Society: $\$ 4.00$ per volume; single issues $\$ 1.50$. Back numbers are available.

Subscriptions, orders for back numbers, and changes of address should be sent to Pacific Journal of Mathematics, 103 Highland Boulevard, Berkeley, California, 94708.

PUBLISHED BY PACIFIC JOURNAL OF MATHEMATICS, A NON-PROFIT CORPORATION

Printed at Kokusai Bunken Insatsusha (International Academic Printing Co., Ltd.), 270, 3-chome Totsuka-cho, Shinjuku-ku, Tokyo 160, Japan. 


\section{Pacific Journal of Mathematics}

\section{Vol. 42, No. $2 \quad$ February, 1972}

Stephen Richard Bernfeld, The extendability of solutions of perturbed scalar differential equations ................................. 277

James Edwin Brink, Inequalities involving $f_{-} p$ and $f^{(n)}{ }_{q}$ for $f$ with $n$

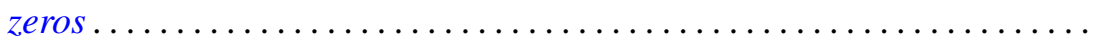

Orrin Frink and Robert S. Smith, On the distributivity of the lattice of filters of a groupoid

Donald Goldsmith, On the density of certain cohesive basic sequences .... 323

Charles Lemuel Hagopian, Planar images of decomposable continua . . . . . 329

W. N. Hudson, A decomposition theorem for biadditive processes ........ 333

W. N. Hudson, Continuity of sample functions of biadditive processes......

Masako Izumi and Shin-ichi Izumi, Integrability of trigonometric series.

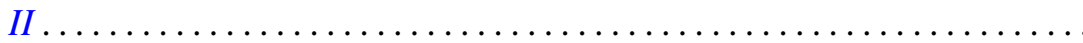

H. M. Ko, Fixed point theorems for point-to-set mappings and the set of

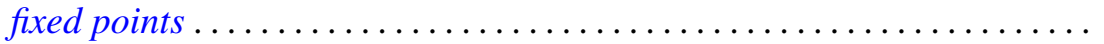

Gregers Louis Krabbe, An algebra of generalized functions on an open interval: two-sided operational calculus ...

Thomas Latimer Kriete, III, Complete non-selfadjointness of almost selfadjoint operators.................................

Shiva Narain Lal and Siya Ram, On the absolute Hausdorff summability of a Fourier series .

Ronald Leslie Lipsman, Representation theory of almost connected groups...

James R. McLaughlin, Integrated orthonormal series.... . .

H. Minc, On permanents of circulants.

Akihiro Okuyama, On a generalization of $\Sigma$-spaces.....

Norberto Salinas, Invariant subspaces and operators of class $(S)$

James D. Stafney, The spectrum of certain lower triangular matrices as operators on the $l_{p}$ spaces .......................

Arne Stray, Interpolation by analytic functions

$\mathrm{Li} \mathrm{Pi} \mathrm{Su}$, Rings of analytic functions on any subset of the complex plane.

R. J. Tondra, A property of manifolds compactly equivalent to compact manifolds.... 